\section{Contrasting methods in determining a DL using two-point tactual stimuli: A TSD approach}

\author{
HENRY A. CROSS, WILLIAM N. BOYER, DONNELL M. WASHINGTON* \\ and GARY W. GUYOT \\ Colorado State University, Fort Collins, Colo. 80521
}

A yes/no fixed-base matching signal detection (TSD) approach was employed to determine a tactual difference limen (DL) with signal stimuli presented symmetrically around a standard. Experiment 1 failed to generate consistent results, but in Experiments 2 and 3 signal stimuli were given unidirectionally and previous findings were extended by showing a two-point tactual DL (dorsal forearm) in excess of $6 \mathrm{~mm}$. The problems encountered in Experiment 1 were considered in the light of the binary TSD model and it was concluded that the basic judgment task was more complex than that dictated by the model.

Fry, Haupt, \& Wartena (1933) employed the method of single stimuli to investigate the supraliminal two-point difference liman (DL). The test was conducted on the right volar forearm with seven aesthesiometers se parated by 1.8 in. The aesthesiometer separated by the smallest distance varied for each $\mathrm{S}$, but it was always above the two-point threshold. The DLs that Fry, Haupt, and Wartena did not compute were computed by the authors. The DLs were ascertained by dividing the interval of uncertainty by one-half, giving DLs of 3.0 and $3.6 \mathrm{~mm}$ for the two Ss reported in the investigation.

Gatti (1937) and Danesino (in Gatti, 1937), in separate experiments, reported DLs of 2.15 and $2.5 \mathrm{~mm}$, respectively, when using a standard of $50 \mathrm{~mm}$. However, since both authors give similar DLs for standards of 10 , 20 , and $30 \mathrm{~mm}$, which are well below the two-point threshold of $40 \mathrm{~mm}$ (Hilgard, 1953), it is difficult to draw conclusions from their results.

Following the suggestion of Underwood (1966) that no one had yet reported a DL of a two-point limen, Cross, Boyer, \& Guyot (1970) used a yes/no theory of signal detection (TSD) approach to determine the supraliminal two-point tactual DL on the dorsal forearm for four Ss. With a standard of $47 \mathrm{~mm}$ and three positive unidirectional signal stimuli in $3-\mathrm{mm}$ steps, it was discovered that the test aesthesiometer must exceed the standard by more than $6 \mathrm{~mm}$ to enable Ss to reliably report "different." However, there were individual differences in the investigation, and one $S$ reliably reported a change at $3 \mathrm{~mm}$.

Washington (1971), using the TSD method, extended the previous findings by focusing on the "ideal

*Captain Donnell M. Washington is now at the U.S. Air Force Academy, Colorado. subject" (Green \& Swets, 1966). Using a standard of $48 \mathrm{~mm}$ with positive unidirectional stimuli of 51,54 , and $57 \mathrm{~mm}$, a single $S$ was given 9 practice sessions and 18 test sessions. Feedback was given after each trial during the 9 practice sessions to maximize "hits" and minimize "false alarms." Seven practice sessions were administered prior to the testing and 2 practice periods were given between the 9 th and 10th testing sessions. Each trial consisted of a warming interval, an observation interval, and an answer interval. Signal previews, which consisted of 6 trials in which $S$ had knowledge of the results, preceded each block of trials. Finally, $\mathrm{S}$ was given information about the a priori distribution of noise and signal trials. Each session consisted of six blocks of 20 trials each, for a total of 120 trials, with 2 -min rest intervals between blocks. Between Blocks 3 and $4, S$ received a $10-\mathrm{min}$ break. Stimuli were also grouped in short blocks in order to provide a separate "false alarm" for each stimulus rather than the "pooled" false alarm as utilized in the Cross, Boyer, and Guyot study. In this comprehensive investigation, Washington reported a DL of $3 \mathrm{~mm}$ for the forearm.

The purpose of this present experiment was to determine the two-point supraliminal DL above and below a standard on the dorsal forearm. The stimuli were presented above and below a standard in order to provide bidirectional evidence for the two-point tactual DL.

\section{EXPERIMENT 1}

The Ss were two graduate male students enrolled at Colorado State University who also served as Es. The apparatus consisted of seven aesthesiometers with the standard set at $50 \mathrm{~mm}$. Three were set in $3-\mathrm{mm}$ steps unidirectional below the standard to provide signal stimuli of 47,44 , and $41 \mathrm{~mm}$, and three others were set in $3-\mathrm{mm}$ steps above the standard to provide signal stimuli of 53,56 , and $59 \mathrm{~mm}$. All of the aesthesiometers were set above the two-point tactual threshold for the forearm of $40 \mathrm{~mm}$ reported by Hilgard (1953)

In the present investigation, a yes/no TSD fixed-base matching procedure was employed. The standard stimulus was always presented first, and it was followed by either the standard stimulus again or with a signal stimulus. Trials were presented in a random order in which one-half involved repetition of the standard and one-half involved presentation of the standard and one of the six signal stimuli. The six signal stimuli were presented throughout each experimental session. Each $\mathrm{S}$ was instructed to make comparative judgments of a set of two stimuli presented successively. He was to respond "same" if the two stimuli of a trial were judged to be the same length and to respond "different" if they appeared to be different in length. This procedure is similar to the fixed-base matching procedure used in psychoacoustics (Sorkin, 1964). If $\mathrm{S}$ reported "different" when the second stimulus of a trial was indeed different, this constituted a "hit"; but if he reported "different" during those trials in which the standard was repeated, this was scored as a "false alarm." The Ss were given information about the a priori distribution of standard-standard and standard-signal trials, which was 0.50 .

This method allowed Es to obtain six points in the ROC unit square for each $S$ with each point reflecting S's sensitivity for a given signal. All other aspects of the procedure have been previously reported (Cross, Boyer, \& Guyot, 1970; Boyer, Cross, Guyot, \& Washington, 1970). Each experimental session consisted of 108 trials, with a total of 12 daily sessions. Thus each standard-standard trial was repeated a total of 648 trials, and each of the six standard-different combinations was presented a total of 108 trials. EXPERIMENTS 2 AND 3

As the results for the two Ss were not entirely consistent with previous findings (Cross, Boyer, \& Guyot, 1970), two additional experiments were conducted on the same Ss. The same basic procedures were employed to investigate the amount of change necessary in a supraliminal two-point tactual task in which only unidirectional signals were used. The same standard and signals were used except that for Experiment 2, the signals 53,56 , and $59 \mathrm{~mm}$ were unidirectional above the standard. For Experiment 3, the signals were all below the standard, 47, 44, and 


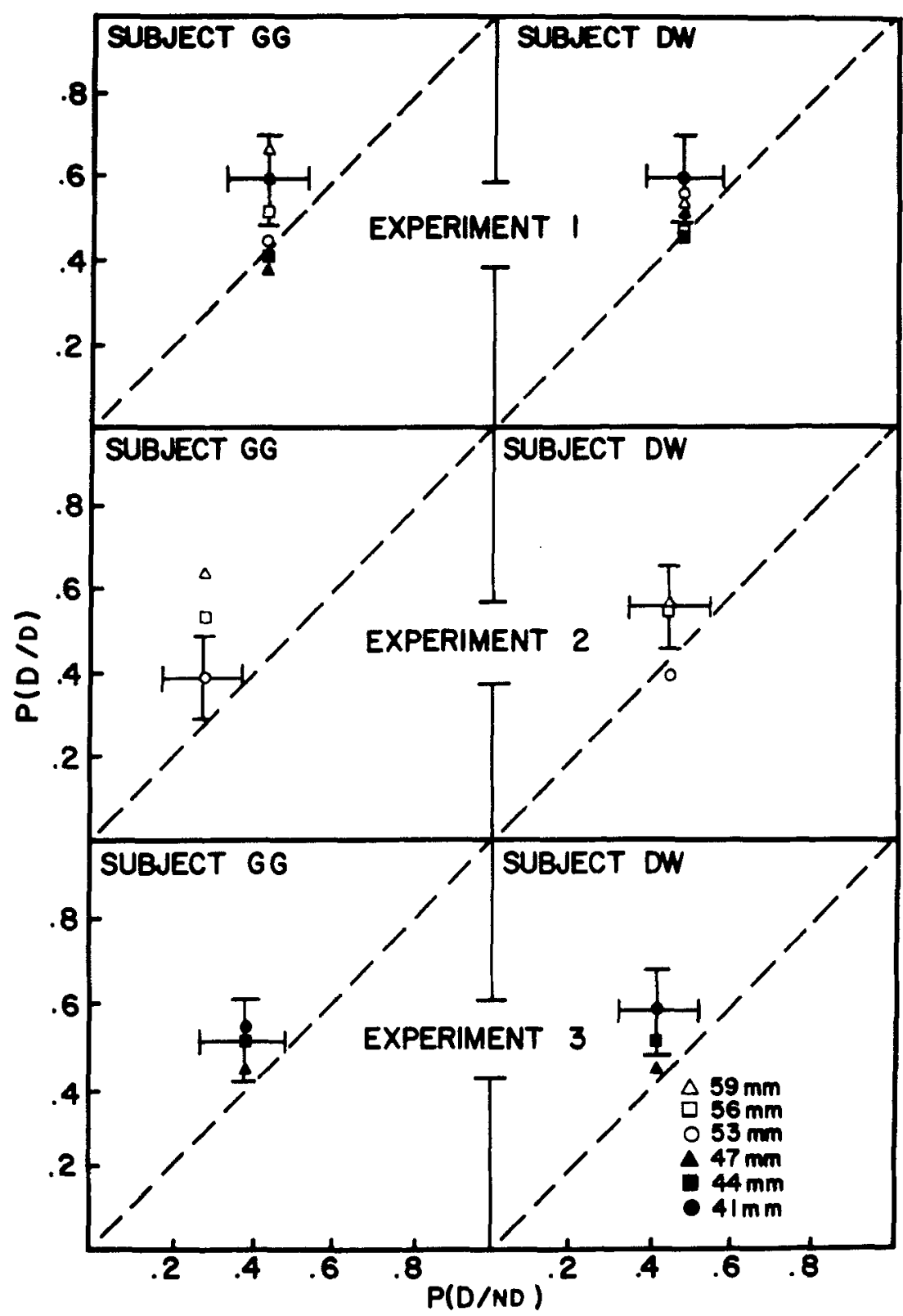

Fig. 1. P(D/D) represents the proportion of "different" responses when the second stimulus was actually different from the standard, and $P(D / N D)$ represents the proportion of "different" responses when the test stimulus was not different from the standard. Bands for the $95 \%$ confidence intervals are shown for the various data points when there is a possible question about statistical significance.

Table 1

Subject Sensitivity and Criterion

\begin{tabular}{|c|c|c|c|c|c|c|c|}
\hline Stimuli & & 41 & 44 & 47 & 53 & 56 & 59 \\
\hline & & \multicolumn{6}{|c|}{ S DW } \\
\hline Symmetrical & $\begin{array}{l}\mathrm{d}^{\prime} \\
\beta\end{array}$ & $\begin{array}{r}.29 \\
1.00\end{array}$ & $\begin{array}{r}.01 \\
1.00\end{array}$ & $\begin{array}{l}.17 \\
.981\end{array}$ & $\begin{array}{l}.22 \\
.993\end{array}$ & $\begin{array}{l}.125 \\
1.00\end{array}$ & $\begin{array}{l}.20 \\
.996\end{array}$ \\
\hline Unidirectional & $\begin{array}{l}\mathrm{d}^{\prime} \\
\beta\end{array}$ & $\begin{array}{r}.44 \\
1.00\end{array}$ & $\begin{array}{r}.25 \\
1.03\end{array}$ & $\begin{array}{r}.13 \\
1.02\end{array}$ & $\begin{array}{r}-.14 \\
.967\end{array}$ & $\begin{array}{r}.22 \\
1.01\end{array}$ & $\begin{array}{r}.26 \\
1.01\end{array}$ \\
\hline Symmetrical & $\begin{array}{l}d^{\prime} \\
\beta\end{array}$ & $\begin{array}{l}.43 \\
.98\end{array}$ & $\begin{array}{r}-.02 \\
1.00\end{array}$ & $\begin{array}{r}-.10 \\
.98\end{array}$ & $\begin{array}{r}.05 \\
1.01\end{array}$ & $\begin{array}{r}.23 \\
1.01\end{array}$ & $\begin{array}{l}.59 \\
.93\end{array}$ \\
\hline Unidirectional & $\begin{array}{l}\mathrm{d}^{\prime} \\
3\end{array}$ & $\begin{array}{r}.38 \\
1.03\end{array}$ & $\begin{array}{r}.30 \\
1.04\end{array}$ & $\begin{array}{r}.15 \\
1.03\end{array}$ & $\begin{array}{r}.30 \\
1.14\end{array}$ & $\begin{array}{r}.74 \\
1.17\end{array}$ & $\begin{array}{r}.94 \\
1.11\end{array}$ \\
\hline
\end{tabular}

$41 \mathrm{~mm}$. Each experimental session consisted of 108 trials, with a total of six daily sessions. Thus, for each experiment, the standard-standard was presented 324 trials and the standard-different combinations were presented 108 trials, comparable to Experiment 1.

\section{RESULTS AND DISCUSSION}

All data were analyzed using binomial ellipses in receiver operating curve (ROC) unit squares. The procedures for analyzing the data are identical to those employed by Cross, Boyer, \& Guyot (1970). The S's sensitivity $\left(d^{\prime}\right)$ to the stimuli and his response criteria $(\beta)$ for each signal stimulus were computed using the methods outlined in Corso (1967). To test statistically for sensitivity, the binomial data point in the unit square was calculated for each test stimulus and two $95 \%$ confidence bands, one for the portion of hits and one for the portion of false alarms, were calculated for each point. These results are shown in Fig. 1 . The $d^{\prime}$ and $\beta$ values for each experiment appear in Table 1.

In Experiment 1, S G.G. showed significant sensitivity at the extreme signals of 41 and $59 \mathrm{~mm}$. D.W. displayed sensitivity only at $41 \mathrm{~mm}$ and had inversions in the middle of both signal distributions, i.e., 44 and $56 \mathrm{~mm}$. These data did not fit the results of our previous findings, in which generally a change in excess of more tha $a_{\lrcorner} 6 \mathrm{~mm}$ enabled $\mathrm{S}$ reliably to report "different." Both Ss reported that the task seemed to be more than binary in nature, i.e., even though a binary same/different response was called for, on any trial there were three possible decision strategies: (1) same, (2) different-smaller, (3) different-larger. Although this problem was not prevalent at extreme values, it appeared to have a detrimental effect on performance at signal values close to the standard.

Since in Experiment 1 a larger standard and larger signals were used than in the previous work (Cross, Boyer, \& Guyot, 1970), it was decided to replicate the original study using the larger standard and signal stimuli. The results from Experiment 2 show that G.G. was sensitive to all signal stimuli, and that there was a statistically significant increase between 53-, 56-, and 59-mm stimuli. D.W. was sensitive only at $59 \mathrm{~mm}$, but both 56 and 59 were statistically different from $53 \mathrm{~mm}$. These results were in accord with the findings of the initial studies.

Experiment 3 involved unidirectional steps below the same standard, using Experiment 1 increments. G.G. was sensitive at both 
41 and $44 \mathrm{~mm}$, but these were not sensitive from each other. D.W. was sensitive at $41 \mathrm{~mm}$, which was also significant from $47 \mathrm{~mm}$, and again there were no inversions. Despite individual differences, the results from Experiments 2 and 3 conform closely to the initial studies. With a unidirectional approach above or below a supraliminal standard, it appears that a test stimulus must generally be changed by more than $6 \mathrm{~mm}$ to enable $\mathrm{S}$ reliably to report "different." The traditional binary yes/no TSD matching procedure works well when used unidirectionally but involves problems when used symmetrically. This is possibly due to the fact that the symmetrical situation involves a task of more complexity than that which is dictated by the binary model.

\section{REFERENCES}

BOYER, W. N., CROSS, H. A., GUYOT, G. W., \& WASHINGTON, D. M. A TSD determination of a DL using two-point tactual stimuli applied to the back. Psychonomic Science, 1970, 21, 195-196.

CORSO, J. F. The experimental psychology of sensory behavior. New York: Holt, Rinehart, \& Winston, 1967.

CROSS, H. A., BOYER, W. N., \& GUYOT, G. W. Determination of a DL using two-point tactual stimuli: A signal detection approach. Psychonomic Science, 1970, 21, 198-199.

FRY F. D. HAUPT, D. D. M. \& WARTENA, L. The DL for cutaneous two-point stimulation by the method of single stimuli. Journal of Experimental Psychology, 1933, 16, 743-744.

GATTI, A. The perception of space by means of pure sensations of touch. American Journal of Psychology, 1937, 50, 289-295.

GREEN, D. M., \& SWETS, J. A. Signal detection theory and psychophysics. New York: Wiley, 1966.

HILG A R D, E. R. Introduction to psychology. New York: Harcourt, Brace \& World, 1962.

SORKIN, R. D. Extension of the theory of signal detectability to matching procedures in psychoacoustics. In $\mathrm{J}, \mathbf{A}$. Swets (Ed.), Signal detection and recognition by human observers. New York: Wiley, 1964.

UNDERWOOD, B. J. Experimental ps ychology. New York: Appleton-Century-Crofts, 1966. Pp. 218-226.

WASHINGTON, D. M. A TSD determination of the two-point supraliminal DLs on the dorsal forearm, the anterior thigh, and the back of the hand. Unpublished master's thesis, Colorado State University, 1971. 